\title{
Evaluation of Critical Success Factors for Telemedicine Implementation
}

\author{
Mariyam Nazviya \\ Assistant Director \\ Decision Support Division \\ Ministry of Health, Maldives
}

\author{
Subrahmanyam Kodukula \\ Professor \\ Department of CSE, KL University \\ Vaddeswaram, Guntur Dt., India
}

\begin{abstract}
Telemedicine has been practiced successfully in many countries with the help of necessary technological and computing resources. However, past attempts to implement telemedicine in Maldives were not successful for various reasons. This qualitative exploratory research study utilised In-depth Individual Interviews, Focus Group Discussions and secondary data analysis has obtained valid findings on what contributed to failure of past projects, along with number of other variables and issues surrounding telemedicine implementation in Maldives. Accordingly the information derived from the research allowed to identify critical success factors for implementing telemedicine in the country. These critical success factors are noted to be , support from government, adopting standardised project management practices, increasing public awareness and acceptance, political support, availability of technological infrastructure, availability of sustainable financial support, clearly defined legislation, defined referral mechanism, adequately trained personnel and proper communication between all stakeholders. The ways to address the barriers and challenges identified were also recommended.
\end{abstract}

\section{General Terms}

Critical Success Factors, Focus Group, Stake Holder, SWOT Analysis

\section{Keywords}

E-health, Tele-health, Telemedicine issues, Telemedicine project management, Referral mechanism, ISP.

\section{INTRODUCTION}

Telemedicine is the use of audio, video, and other telecommunications and electronic information processing technologies to provide health services or assist health care personnel at distant sites [1]. Although it has been practiced successfully in many countries, in Maldives it has not yet been successfully implemented. The archipelago of Maldives comprising of 1190 islands, and the dispersed nature of these islands makes the country an ideal place to implement telemedicine. However, past attempts to implement telemedicine were not successful for various reasons. As such, this study was undertaken to explore the issues surrounding telemedicine implementation and to analyse the primary data as well as secondary data to identify the critical success factors for telemedicine implementation in Maldives. The research aims and objectives were based on an extensive literature review on the telemedicine situation. A theoretical framework based on
Technology-Environment-Organisation model formed the foundations for the qualitative exploratory study. Data collected was analysed to discuss the issues surrounding telemedicine implementation and the critical success factors in the Maldivian context before concluding the main outcomes of the research and provide recommendations.

\section{RESEARCH AIMS AND OBJECTIVES}

The major aim of this research is "to critically evaluate factors affecting the success of telemedicine projects in Maldives". Specific objectives included the following:

i. To synthesise on available literature and previous telemedicine projects to find the factors affecting telemedicine in Maldives.

ii. To carry out interviews and discussions with relevant people to understand and analyse the common barriers hindering successful implementation of telemedicine and to identify the success factors for implementing telemedicine.

iii. To provide recommendations for implementing telemedicine successfully in Maldives by reviewing existing standards and correlating to findings of this research.

\section{TELEMEDICINE AND ITS APPLICATION}

Telemedicine has been practiced in different parts of the world even as early as in 1910 when Einthoven's used ordinary telephones to transmit Electrocardiograms (ECGs) and Electroencephalogram (EEGs) to help diagnose medical conditions [2]. Over the past thirty years, the use of telemedicine has widened mainly because of improved digital imaging technology, reduction in transmission cost and increased accessibility of technology and real time transmission of data [3]. Innovations and advancements in technology each year brings more efficiency to the existing telemedicine systems and it is expected that in future telecommunication services will be more cheaper hence increasing the feasibility of adopting telemedicine as part of routine medical provision.

Telemedicine offers a wide range of advantages. The main benefit realised through telemedicine is the increased accessibility of health care to the rural area from the developed urban centres providing specialised care. Several authors have highlighted the benefits of telemedicine and the increased accessibility the technology allows to health services. Distance and problems with 
travelling to seek medical assistance from hospitals offering more specialist services has always been a barrier impacting on the health status of people living in the rural areas as compared to urban areas [4]. For cases requiring urgent treatment if an appropriate telemedicine infrastructure exist, the time to travel and obtain proper medical assistance is greatly reduced. Hence telemedicine has the potential to save lives if implemented in an appropriate manner [5]. Additionally, telemedicine lower the cost not only for the patient but also to the governing health bodies and insurance companies [6]. Although it is recognised that telemedicine do have benefits and offers medical services to areas where normally it is difficult to reach, it has to be kept in mind that consultation done through telemedicine can never be as good as real consultation where the treating doctor will be able to assess and see the conditions of the patient first hand [7].

\subsection{Maldivian Telemedicine situation}

Maldives being an island nation comprising of 1190 islands with a population of about 300,000 people makes it an ideal place to implement telemedicine. Due to the geographical distribution of the islands and the population distribution, there are several problems faced by the Maldivian society. People in the rural islands have to seek medical attention from health facilities in larger islands and therefore transportation cost imposes as a major problem. In 2002 the first Telemedicine project was developed by the government as the 'Health Telematics Project' funded by World Health Organisation. However due to several reasons the project did not work out as planned. Another initiative undertaken in the year 2004 is the Telemedicine Project (a component of Integrated Human Development Project (IHDP)) funded by World Bank [8]. Although telemedicine projects were planned and executed, none of it resulted in success. . It was suspected that more than the technical issues, factors such as poor project management, improper risk assessment and human factors that contributed to failure of the past telemedicine projects. As such this was kept in mind when the theoretical framework and research instruments were developed for the study.

\section{THEORETICAL FRAMEWORK}

The framework that was applied to the Maldivian telemedicine situation was the Technology-Environment-Organisation Framework or TEO framework which was developed by Tornatzky and Fleisher [9].

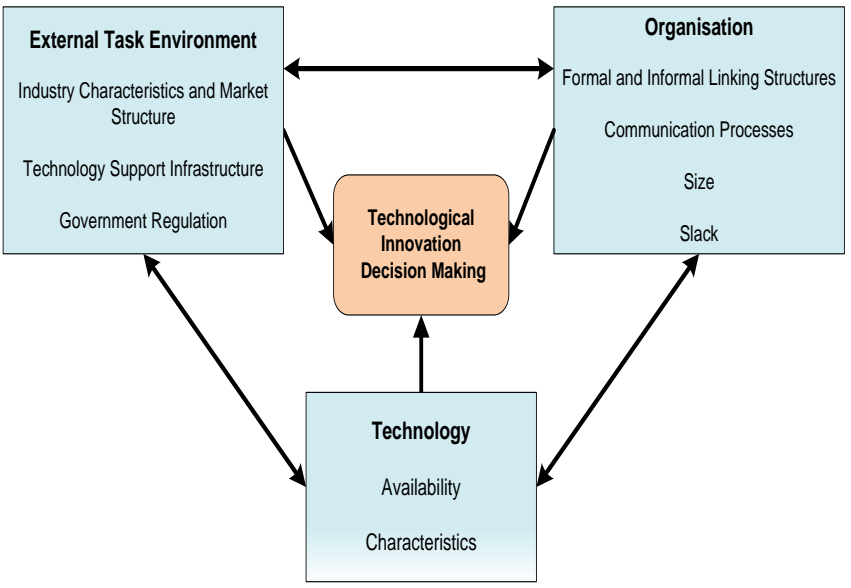

Figure 1: Technology-Environment-Organisation Framework
When the TEO framework is applied to certain processes or scenarios, it helps to establish the way the organisation sees the need for technology, searches and adopts the new technology. Application of the three elements in the framework to telemedicine situation in Maldives will allow establishing an understanding of both opportunities and constraints which in turn will ultimately lead to identification of critical success factors for implementing telemedicine in Maldives. Thus, such an in-depth analysis of all factors affecting the success of telemedicine was evaluated in this qualitative research.

\section{RESEARCH APPROACH}

A qualitative exploratory study design was adopted, as the main objective of the research is to understand and review in-depth the issues surrounding telemedicine in Maldives. Qualitative research methods will assist researchers to understand people, situations and organisations in a social and cultural context in which they exist [10]. It is recommended to have exploratory qualitative study if the purpose is to acquire in-depth knowledge to understand factors affecting a situation which relates more to the aim of this research [11][12][13]. Secondary data from published and unpublished documents was contributed to understand the telemedicine situation in the Maldivian context.

The primary data was collected from Individual-depth Interviews (IDI), and Focus Group Discussion (FGD). The data was collected from two main sites in Maldives, namely, Male', the central capital island of the country and Kulhudhuffushi island in the north province of the country, where previous telemedicine projects were implemented. Attempts were made to obtain data from other parts of the rural areas in the country via electronic form. The following four target groups were included in this research to get perspective and understanding from different angles.

$\begin{array}{cl}\text { i. } & \text { Policymaker / Manager Group } \\ \text { ii. } & \text { Clinician Group } \\ \text { iii. } & \text { Technical / Support Staff Group } \\ \text { iv. } & \text { People / End-user Group }\end{array}$

As this research was a qualitative research, the sampling methodology adopted for this research was non-probability sampling or purposive sampling, an approach which is initiated with a purpose to obtain specific information and which will usually have two or more predefined groups. The aim of purposive sampling is not to obtain statistically significant numeral information but rather obtain qualitative information and obtain in-depth understanding of given situations [9].

Some of the strategies within non-purposive sampling like heterogeneous sampling, homogenous sampling, critical case sampling and self selection sampling were utilised in this research which were illustrated in Figure 2 \& 3 below. 


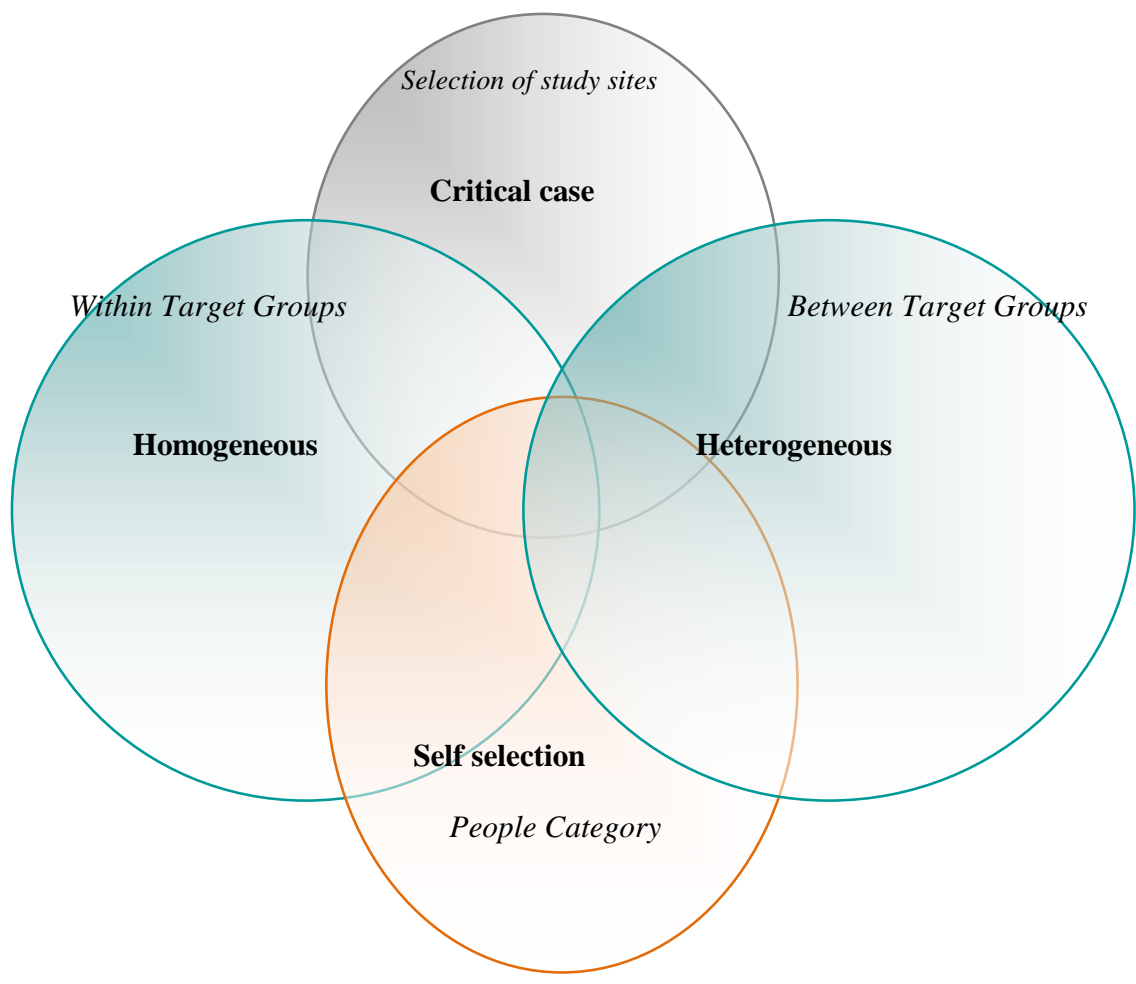

Figure 2: Non probability sampling strategies adopted in the research 


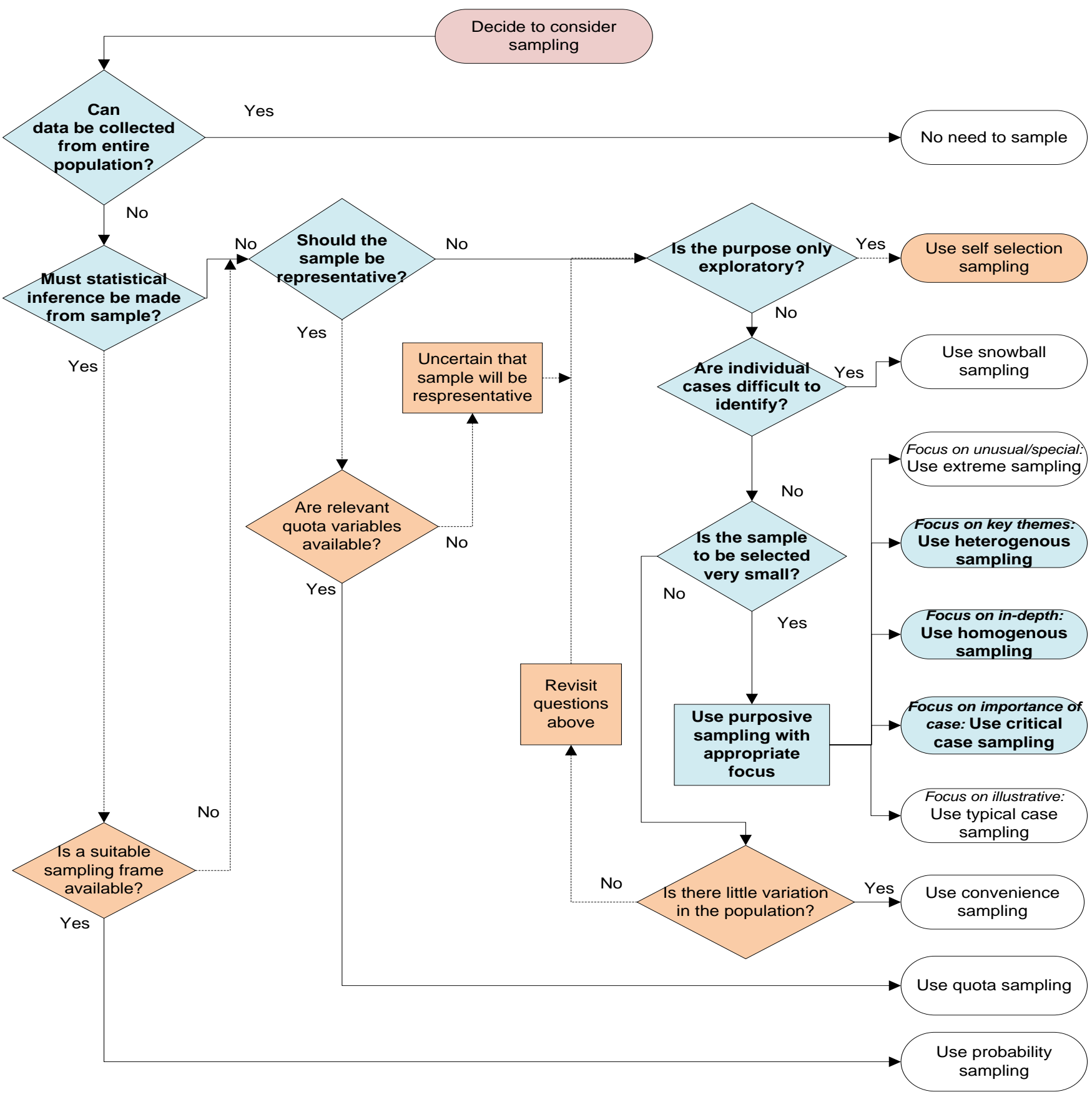

\section{LEGEND:}

Blue coloured icons, Bold font: process followed for: Policymaker/Manager Group, Clinician Group \& Technical Support Staff Group Orange coloured icons, dotted line: process followed for People Group

Figure 3: Sampling process adopted in the research

Data collection was facilitated primarily by the semi-structured interview questionnaire with open ended questions designed to assist descriptive gathering of information. Different questionnaires were administered to the four different Target Groups although the modifications were minor and majority of questionnaire comprised of common questions. Except for
People / End User category, each interview was audio recorded and some interviews were video recorded. Notes were also taken during the interview process on printed semi structured questionnaire to allow for triangulation of data. The interviews were conducted during scheduled times allocated at the convenience of the participants. Once the data was collected it 
was transcribed. The transcribed data was double checked with the recordings to ensure the quality of data. As a result of this cross checking appropriate data cleaning was done. Manual coding of the transcribed data in Microsoft Excel assisted to identify the themes and patterns in the data.

As one of the target groups is People/End-user category, the inclusion criteria for which was the general population attending to hospital seeking outpatient services. The interviews with these potential patients involved getting a perspective from patients' point of view. Hence ethical aspects were carefully considered during the research process. Consistent with this, the research proposal for this dissertation was submitted to the National Health Research Committee in Maldives for approval before initiating the study. The study was conducted after obtaining written approval from the Maldives National Health Research Committee. checked before entering the data to a Microsoft Excel spreadsheet. A manual process of data entry, manual data coding and assigning of categories were done on the raw data file before analysing and drawing conclusions from it.

Based on the evaluation of the findings of the research, the critical success factors for implementing telemedicine can be closely linked to the TEO Framework. The finding when applied to the model brings on some modifications as illustrated in Figure 4 below:

\section{RESEARCH FINDINGS}

All the interviews were carefully transcribed, cross checked with audio as well as available video recordings. Data was cleaned and

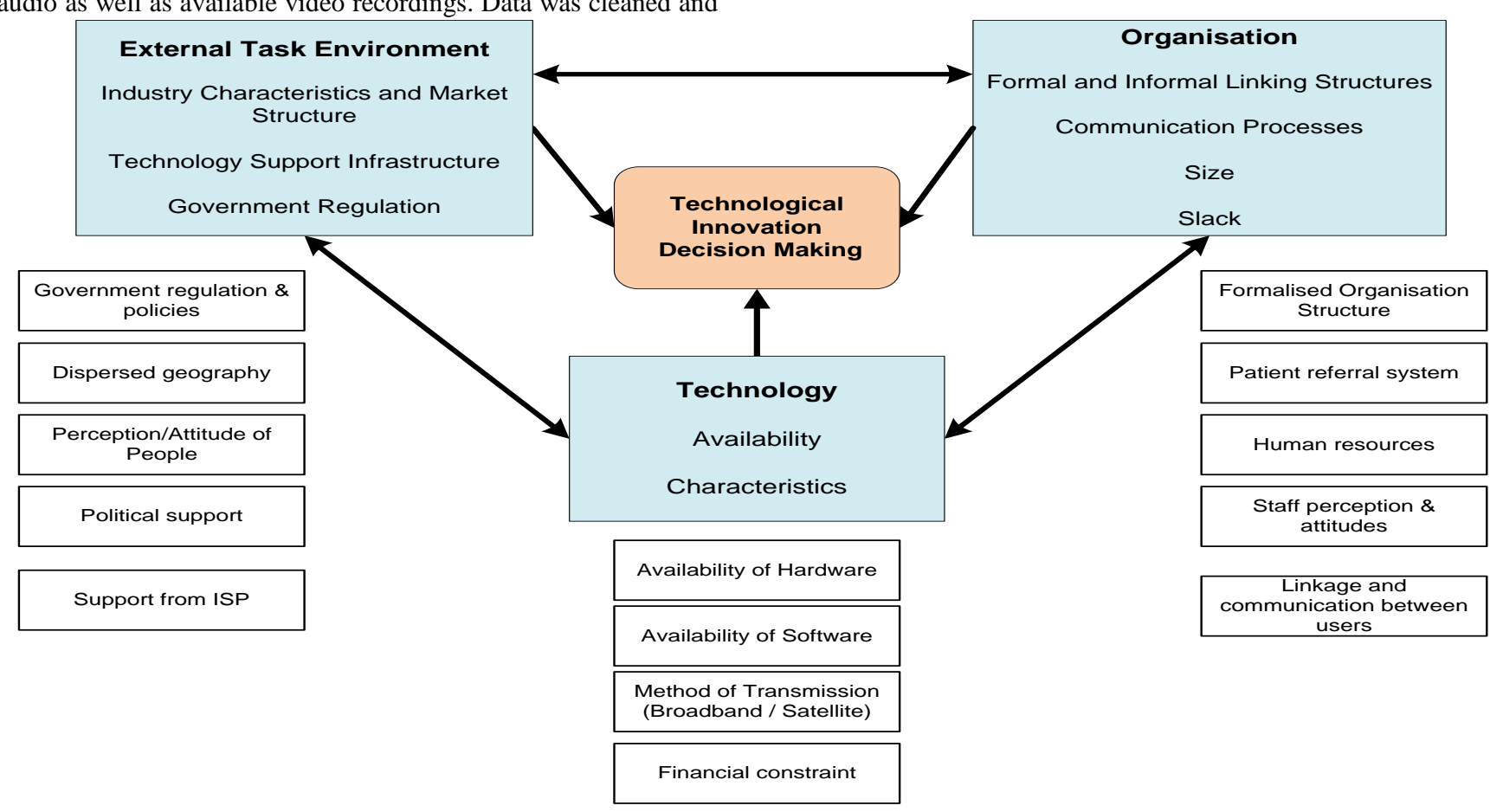

Figure 4: Application of results to the TEO Model

The Critical Success Factors (CSF) can be defined as a limited number of characteristics, conditions or variables that has a direct impact on viability, efficiency and effectiveness of a project, program or an organisation [14]. Based on the findings of this research it is noted that CSF for implementing telemedicine are:
a) Supporting Government Regulations and Policies
b) Adopting standardised Project Management practices
c) Acceptability of public
d) Political Support
e) Availability of Technological Infrastructure including hardware, software and adequate bandwidth

f) Availability of sustainable funds

g) Clearly defined legislation

h) Clearly defined telemedicine referral mechanisms and protocols

i) Adequate trained human resources

j) Communication and linkage between stakeholders.

The analysis of the data also assisted to identify the key stakeholders for telemedicine projects in Maldives and these were noted to be (a)- Policymakers and managers (including those in rural islands) (b)- Clinical staff (doctors, nurses, community 
health workers) (c)- Information Technology support staff, (d)Internet Service Providers and (e)- End-users or public.

The common barriers and challenges for telemedicine implementation in Maldives were identified to be financial constraints, limitation of technological infrastructure, limitation of human resource capacity in the rural areas, lack of public awareness and community sensitisation on telemedicine, limitation of trust within the health system, commitment from politicians, commitment from other stakeholders and limitations on the legislative support for telemedicine.

Some of the ways these barriers and challenges could be addressed are noted to be as follows:

a) Financial constraint: advocate the use of telemedicine and the potential benefits to the Maldivian society so that external donors and funding agencies will be justified in investing telemedicine activities.

b) Technological infrastructure: explore options that are most feasible and involve the ISP to understand and to get an overview of technological infrastructure such as the egovernment network or other such networks which can be shared to generate cost effective results.

c) Human resource capacity: Allocating budget specifically for short term and long term training and sending committed staff to take part in these trainings.

d) Community or public sensitisation: Having awareness programs through the public media, conferences and workshops on the benefits with telemedicine.

e) Building trust within the health system: This is a challenge that will take time to accomplish as people's perception and trust can be build over a period of time, given that quality system exists in practice.

f) Political commitment: Steadfast commitment from ministers and other political people has to be in place by the government so that it reflects on the existing policies of the health sector.

g) Commitment from all stakeholders: commitment can be increased by active participation of all stakeholders and making them more involved in the Systems Development Life Cycle.

h) Legislative support: legal experts need to be involved from the beginning to formulate legislations pertaining to telemedicine and include the relevant components in legal documents such as The Health Act or Patient Confidentiality Act.

\section{RECOMMENDATIONS}

Based on the findings of the study authors have given below recommendations for consideration for successful implementation of telemedicine in Maldives.

a) Stakeholders need to be made aware of standardised project management practices and empowered so that it can be utilised in telemedicine projects as well as other projects within the health sector. This will contribute to overall improvements in planning, managing, organising, sustaining and monitoring of telemedicine activities. b) A proper SWOT (Strength, Weakness, Opportunity and Threats) analysis needs to be undertaken and assessed, so that the issues can be properly addressed during the planning of telemedicine projects.

c) A proper Cost Benefit Analysis (CBA) needs to be done to assess the actual benefits realised through telemedicine. Such an analysis and weighing scale approach will be able to determine the actual benefits and associated costs so that it could be determined if it is worth investing in such a project. Although a lot of potential and benefits are seen with telemedicine implementation at first, in-depth analysis of qualitative data presented in this research shows that there may be a lot of significant underlying issues which may lead to decreased efficacy of telemedicine implementation. For example is it worth to invest so much in telemedicine if the actual numbers of cases are so low that effectiveness is not seen in the system?

d) It is recommended to have a quantitative study on the perspective of general public so that more factors relating to perception of public is uncovered and any issues are addressed in the planning of telemedicine projects.

e) Further research needs to be undertaken by experts of qualitative research to re-evaluate telemedicine concepts within a timeframe which allows comprehensive analysis with adequate time.

f) Once telemedicine system is established, regular monitoring of telemedicine activities should be taken and field visits to be conducted for monitoring the process and contribute to quality of service.

g) It is recommended to enforce capacity building and trainings programs in this field to address the shortage of trained personnel in the health sector. Training of Trainees (TOTs) can be conducted once an initial batch of employees from both central level and island level are trained.

\section{CONCLUSIONS}

This qualitative exploratory research carried out on implementing telemedicine in Maldives has identified several CSF namely supporting Government Regulations and Policies, adopting standardised Project Management practices, increasing public acceptance, increased political commitment and support, availability of technological infrastructure, availability of financial support, clear definition of legislation, clearly defined protocols and referral mechanisms, trained personnel, and communication among stakeholders.

Though the data is gathered through three research strategies like interviews, secondary data analysis and Focus Group Discussions (FGD), where authors were able to conduct 31 interviews and only one FGD, authors consider this as a limitation of the study as more such discussions (FGD) will help to generate more information and clarity in understanding.

Although it will take a lot of commitment, time and effort to address these critical success factors, the long term benefit of increased accessibility and improving the health status of the country maybe worth the investment. Long term cost benefits are 
also expected to be seen with proper implementation and success of telemedicine projects.

\section{ACKNOWLEDGEMENTS}

The data collection for this research would not have been possible without the cooperation and assistance of World Health Organisation, Ministry of Health and many people from Maldives. Authors would like to express sincere gratitude for all the people who contributed to this research by providing their valuable time, insight, views and thoughts during the data collection phase.

\section{REFERENCES}

[1] American College of Physicians. (2009) Telemedicine, Emerging Medical Technology for the Present and Future. [Online]. Available at: http://www.acponline.org/medical_students/resources/news letter/winter 2002.htm (Accessed:12 May 2010).

[2] Stanberry, B. (2000) 'Telemedicine: barriers and opportunities in the 21st century', Journal of Internal Medicine, 247 (6), pp. 615-628.

[3] Miller, T. W., Clark, J., Veltkamp, L. J., Burton, D. C. \& Swope, M. (2005) 'Teleconferencing Model for Forensic Consultation, Court Testimony, and Continuing Education', Behavioral Sciences and the Law, 26 (3), pp. 301-313.

[4] Michael, G. \& Kienzle, M. D. (2001) 'Coming Up Short: Telemedicine's Promise in Perspective', The Journal of Rural Health, 17 (1), pp. 14-15.

[5] Stanberry, B. (2000) 'Telemedicine: barriers and opportunities in the 21st century', Journal of Internal Medicine, 247 (6), pp. 615-628.

[6] Rafiq, A. \& Merrell, R. C. (2005) 'Telemedicine for access to quality care on medical practice and continuing medical education in a global arena', Journal of Continuing Education in the Health Professions, 25 (1), pp. 34-42.

[7] Milstein, R. (1999) Telemedicine - Creating Virtual certainty out of Remote Possibilities. Victoria: Department of Human Services [Online]. Available at: http://www.dhs.vic.gov.au/ahs/archive/telemed/index.htm (Accessed: 14 August 2009).

[8] Ministry of Health (2009), Integrated Human Development Project report, Ministry of Health, Male.

[9] Trochim, W. M. (2006) Research Methods Knowledge Base. Atomic Dog Publishing [Online]. Available at: http://www.socialresearchmethods.net/kb/sampnon.php (Accessed: 18 July 2009).

[10] Myers, M. D. (1997) 'Qualitative Research in Information Systems', MIS Quarterly, 21 (2), pp. 241-242 MISQ Discovery archival version [Online]. Available at: http://www.qual.auckland.ac.nz/ (Accessed: 17 July 2010).

[11] Ghauri, P. \& Gronhaug, K. (2005) Research Methods in Business Studies. 3rd edn. Harlow: Pearson Education Limited.
[12] Saunders, M., Lewis, P. \& Thornhill, A. (2007) Research Methods for Business Students. 4th edn. Harlow: Pearson Education Limited.

[13] Cooper, D., R \& Schindler, P., S (2008) Business Research Methods. 10th edn. New York: The McGraw-Hill Companies, Inc.

[14] Business Directory. (2009) Critical Success Factor Definition. [Online]. Available at: http://www.businessdictionary.com/definition/criticalsuccess-factors-CSF.html (Accessed: 19 August 2010).

[15] American Telemedicine Association. (2009) What is Telemedicine \& Telehealth? [Online]. Available at: http://www.americantelemed.org/files/public/abouttelemedi cine/What_Is_Telemedicine.pdf (Accessed: 23 July 2010).

[16] Berthold, J. (2009) Help from afar: telemedicine vs. telephone advice for stroke. [Online]. Available at: http://www.acpinternist.org/archives/2009/04/telestroke.ht m (Accessed: 16 August 2010).

[17] Brown, N. (1995) A Brief History of Telemedicine. [Online]. Available at http://tie.telemed.org/articles/article.asp?path=articles\&arti cle=tmhistory_nb_tie95.xml (Accessed: 10 July 2009).

[18] Bryman, A. \& Bell, E. (2007) Business Research Methods. 2nd edn. New York: Oxford University Press Inc.

[19] Darkins, A. W. \& Cary, M. A. (2000) Telemedicine and Telehealth - Principles, Plicies, Performance and Pitfalls. Springler Publishing Company [Online]. Available at: http://books.google.com.my/books?hl=en\&lr=\&id=0GY51 ZBY0J8C\&oi=fnd\&pg=PR7\&dq=Advantages+of + Telehea lth\&ots=NM6vNgolJo\&sig=SnkdhrLnw4Zd-smj8vs7Vd8 Hq-E\#v=onepage \&q=Advantages $\% 20$ of $\% 20$ Telehealth\&f =false (Accessed: 14 August 2010).

[20] Fieger (2004) Integrated Human Development Project Implementation Plan. Male' [unpublished].

[21] Fitch, C. J., Briggs, J. S. \& Beresford, R. A. (2000) 'System issues for successful telemedicine implementation', Health Informatics Journal, 6 (3), pp. 166-173.

[22] Hersh, W. R., Hickam, D. H., Severance, S. M., Dana, T., L, Krages, K. P. \& Helfand, M. (2006) Telemedicine for Medicare Population: Update. Rockville: Agency for Healthcare Research and Quality, (131) [Online]. Available at: http://www.ahrq.gov/downloads/pub/ evidence/pdf/telemedup/telemedup.pdf (Accessed: 15 August 2010).

[23] Karamanoukian, H. L., Pande, R. U., Patel, Y., Freeman, A. M., Aoukar, P. S. \& D'Ancona, G. (2004) 'Telerobotics, Telesurgery and Telementoring', Paediatric Endosurgery \& Innovative Techniques, 7 (4), pp. 421-425 Mary Ann Liebert Inc. [Online]. Available at: http://www.liebertonline.com/doi/abs/10.1089/109264103 322614295? cookieSet=1\&journalCode=pei (Accessed: 25 July 2010).

[24] Li, J., Wilson, L., Stapleton, S. \& Cregan, P. (2006) Australia Conference on Computer-Human Interaction: 
Design of an Advanced telemedicine system for emergency care. Sydney 20-24 November 2006. New York: ACM.

[25] Manos, D. (2009) 'White House Budget makes HIT a priority', Healthcare IT News, 8 May 2009 [Online]. Available at: http://www.healthcareitnews.com/news/ white-house-budget-makes-hit-priority (Accessed: 12 July 2010).
[26] Mishra, S. K. (2007) Telemedicine Projects in Maldives Evaluation Report. Male': Ministry of Health [unpublished].

[27] Rafiq, A. \& Merrell, R. C. (2005) 'Telemedicine for access to quality care on medical practice and continuing medical education in a global arena', Journal of Continuing Education in the Health Professions, 25 (1), pp. 34-42. 